\title{
The Effect of Tin-Protoporphyrin on Bilirubin Conjugation and Production in Cholestatic Rats
}

\author{
SHARON FELBER, PHILIP ROSENTHAL, AND DONABY HENTON \\ Department of Pediatrics, Division of Digestive Diseases and Nutrition, University of Southern California School \\ of Medicine and Childrens Hospital of Los Angeles, Los Angeles, California 90027
}

\begin{abstract}
Tin-protoporphyrin (SnP) is actively being investigated for treatment of exaggerated neonatal hyperbilirubinemia. Because both bilirubin conjugation and excretion are immature in the human newborn, we investigated the effect of SnP on bilirubin-conjugating mechanisms and the efficacy of SnP in suppressing serum bilirubin levels in adult rats made cholestatic by surgical bile duct ligation. Male Sprague-Dawley rats received SnP(100 $\mu \mathrm{mol} / \mathrm{kg}$ body weight) subcutaneously either $24 \mathrm{~h}$ before or 24 or $48 \mathrm{~h}$ after bile duct ligation. Serum and urine specimens were collected $72 \mathrm{~h}$ after bile duct ligation and analyzed for bilirubin and its conjugates. As compared to a control group that received bile duct ligation and a sodium phosphate buffer injection, all SnP-treated animals had a significant lowering of total serum bilirubin levels. No differences in the distribution of serum bilirubin mono- and diconjugates in serum or urine samples were observed. However, the concentrations of covalently linked bilirubinprotein conjugates were significantly higher in the control cholestatic rats when compared to the SnP-treated animals. SnP effectively lowers serum bilirubin levels in rats with an impaired biliary excretory pathway for SnP. There was no adverse effect on bilirubin conjugation and no observable toxicity. (Pediatr Res 23: 163-166, 1988)
\end{abstract}

\section{Abbreviations}

SnP, tin-protoporphyrin

AM-HPLC, alkaline methanolysis-high-performance liquid chromatography

ANOVA, analysis of variance

$\mathrm{SnP}$ is being actively investigated as potential therapy for exaggerated neonatal hyperbilirubinemia. A synthetic heme analog, this metalloporphyrin is a potent competitive inhibitor of heme oxygenase $(1,2)$, the initial and rate-limiting enzyme in the sequence of heme degradation and bilirubin production (3). Normal cleavage and oxidation of the heme tetrapyrrole ring by heme oxygenase produces equimolar amounts of carbon monoxide and biliverdin. Inhibition of heme oxygenase by $\mathrm{SnP}$ was demonstrated in cholestatic rats by monitoring serum bilirubin and carbon monoxide production $(4,5)$. A significant decrease in carbon monoxide generation was observed after SnP administration, whereas untreated rats with bile duct obstruction demonstrated an increase in bilirubin production.

SnP has effectively lowered serum bilirubin levels in neonatal

Received August 13, 1987; accepted September 25, 1987.

Correspondence and reprint requests Philip Rosenthal, M.D., Division of Digestive Diseases and Nutrition, Childrens Hospital of Los Angeles, 4650 Sunset Boulevard, Los Angeles, CA 90027.

Supported in part by a grant from the J.B. and Emily Van Nuys Charities. rats (1), rhesus monkeys (6), adult mice (7), mice with unconjugated hyperbilirubinemia the result of hemolytic anemia (8), and in a limited number of adult human volunteers with Gilbert's syndrome (5). Toxicity has been mild, with the predominant side effect reported being skin photosensitivity $(5,9)$. Pharmacologic studies reveal that after either subcutaneous, or intravenous administration, SnP is rapidly absorbed and cleared from the plasma compartment $(10,11)$. Excretion occurs initially in the urine with more gradual clearance and recovery in the feces (11). Of note, only a minority of the administered dose is readily recovered with a major portion of the $\mathrm{SnP}$ dose persisting in the tissues more than $20 \mathrm{~h}(11,12)$. Presumably, in cholestatic conditions, recovery of $\mathrm{SnP}$ is further reduced with impairment of the major excretory route. Little information exists regarding the effects of cholestasis on $\mathrm{SnP}$ metabolism and its activity in suppressing hyperbilirubinemia. Because the human neonate is considered physiologically cholestatic, the metabolism of SnP may be altered since biliary excretion is impaired $(13,14)$. Our experiments were designed to characterize the bilirubin fractions in the serum and urine of SnP-treated adult cholestatic rats, and to compare these values with the bilirubin fractions found in cholestatic rats without SnP treatment. By this approach, we assessed any effects of $\mathrm{SnP}$ on bilirubin conjugating mechanisms. Further, our studies were designed to compare the time of SnP administration regarding cholestatic injury and its efficacy in suppressing serum bilirubin levels.

\section{MATERIALS AND METHODS}

Animal preparation. Adult male Sprague-Dawley rats (Charles River Laboratories, Wilmington, MA) weighing 350-500 g were used in these studies. Four groups were studied consisting of one control group and three experimental groups.

After intraperitoneal pentobarbital administration $(50 \mathrm{mg} / \mathrm{kg}$ body weight), all animals underwent common bile duct ligation via a midline laparotomy. The common bile duct was localized and two ties were made using 3-0 silk. The bile duct was then excised between the two ligatures. The abdominal incision was closed utilizing a running suture of 4-0 silk. After the surgery, the animals were returned to their individual cages. The rats had free access to water and rat Chow (Purina, St. Louis, MO). All animals received identical treatment regarding diet and pre- and postoperative care.

Experimental design. After bile duct ligation, we were concerned that serum bilirubin conjugate concentrations might be so great that concentration changes caused by SnP might not be readily detectable. Therefore, to improve discrimination, SnP administration was varied in time pre- and postligation as outlined below.

Group I. The control group consisted of six animals. Each animal received a sodium phosphate buffer injection $(1 \mathrm{ml})$ subcutaneously at the time of bile duct ligation.

Group II. Six animals received a single dose of SnP subcuta- 
neously (100 $\mu \mathrm{mol} / \mathrm{kg}$ body weight) $24 \mathrm{~h}$ prior to bile duct ligation.

Group III. Six animals received a single dose of SnP subcutaneously ( $100 \mu \mathrm{mol} / \mathrm{kg}$ body weight) $24 \mathrm{~h}$ after bile duct ligation.

Group IV. Five animals received a single dose of SnP subcutaneously $(100 \mu \mathrm{mol} / \mathrm{kg}$ body weight $) 48 \mathrm{~h}$ after bile duct ligation.

Blood samples were obtained via cardiac puncture $72 \mathrm{~h}$ after bile duct ligation. Samples were protected from light in aluminum foil-wrapped containers. The serum was separated by centrifugation, stored in the dark at $-70^{\circ} \mathrm{C}$, and analyzed within 1 wk of collection.

Urine samples were obtained by bladder aspiration under direct visualization $72 \mathrm{~h}$ after bile duct ligation. Sodium ascorbate and disodium EDTA were added to the collection tubes to stabilize the bilirubin conjugates. The samples were protected from light, stored in the dark at $-70^{\circ} \mathrm{C}$, and analyzed within 1 wk.

Reagents. SnP IX (product 749-9) was obtained from Porphyrin Products, Inc., Logan, UT. SnP for injection was prepared by dissolving the salt in $0.2 \mathrm{M}$ sodium phosphate $\mathrm{pH} 12$. The $\mathrm{pH}$ was adjusted to 7.6 using $1 \mathrm{~N} \mathrm{HCl}$ with sufficient water added to give a final molarity of $0.1 \mathrm{M}$, and used within $3 \mathrm{~h}$.

The injection for control animals consisted of $1 \mathrm{ml}$ of $0.1 \mathrm{M}$ sodium phosphate buffer $\mathrm{pH}$ 7.6. All reagents were purchased from commercial sources and were analytical-reagent grade.

Analytical techniques. Serum and urine bilirubin fractions were determined using AM-HPLC (15). This method quantitatively converts bilirubin monoester and diester conjugates to their corresponding monomethyl and dimethyl ester conjugates, which are extracted into chloroform and separated by HPLC. Xanthobilirubic acid methyl ester (Porphyrin Products, Inc.) was used as an internal standard. AM-HPLC allows individual measurement of unconjugated bilirubin, the two bilirubin monoconjugates $\mathrm{C}-8$ and $\mathrm{C}-12$, corresponding to the carbon of the tetrapyrrole skeleton at which the conjugating moiety is attached to the proprionic acid side chain, and diconjugated bilirubin at concentrations of as little as $0.012 \mathrm{mg} / \mathrm{dl}(15)$. The serum sample size used for alkaline methanolysis was 50 or $100 \mu \mathrm{l}$.

Bilirubin-protein conjugates in serum were assayed using a solvent precipitation method (16). This procedure is based on selective removal of the serum bilirubins that are reversibly bound to serum protein by extraction into organic solvents and measurement of the bilirubin protein conjugates in the remaining denatured protein pellet by a diazo method. This method for measurement of bilirubin covalently linked with protein demonstrates quantitative recovery of bilirubin-protein conjugates $>95 \%, \leq 5 \%$ coefficient of variation, and is linear between 3 and $170 \mu \mathrm{mol} /$ liter.

Statistical analysis. Differences between means of group data were tested for significance using one-way ANOVA; $p \leq 0.05$ was considered to be significant. All data are expressed as mean $\pm \mathrm{SD}$. This study was approved by the Animal Care Committee (no. 09-87) of Childrens Hospital of Los Angeles.

\section{RESULTS}

Figure 1 demonstrates the effect of $\mathrm{SnP}$ administration on mean serum bilirubin concentrations. As compared to the control group, all SnP-treated animals had a significant lowering of serum bilirubin levels $(p<0.001)$. Rats in group II, which received $\mathrm{SnP}$ treatment prior to bile duct ligation, had the lowest numerical serum bilirubin concentrations; these levels were not statistically different from the other SnP-treated groups.

Figure 2 represents the distribution of the 2 bilirubin monoconjugates (C-8 and C-12) and diconjugates in the serum of the SnP-treated and control groups. For the purposes of illustration the data for the SnP-treated groups have been pooled because there were no differences in the percentage of the total serum bilirubin contributed by the mono- or diconjugates among the rats receiving $\mathrm{SnP}$. SnP administration, regardless of the time in relation to bile duct ligation, did not significantly alter the

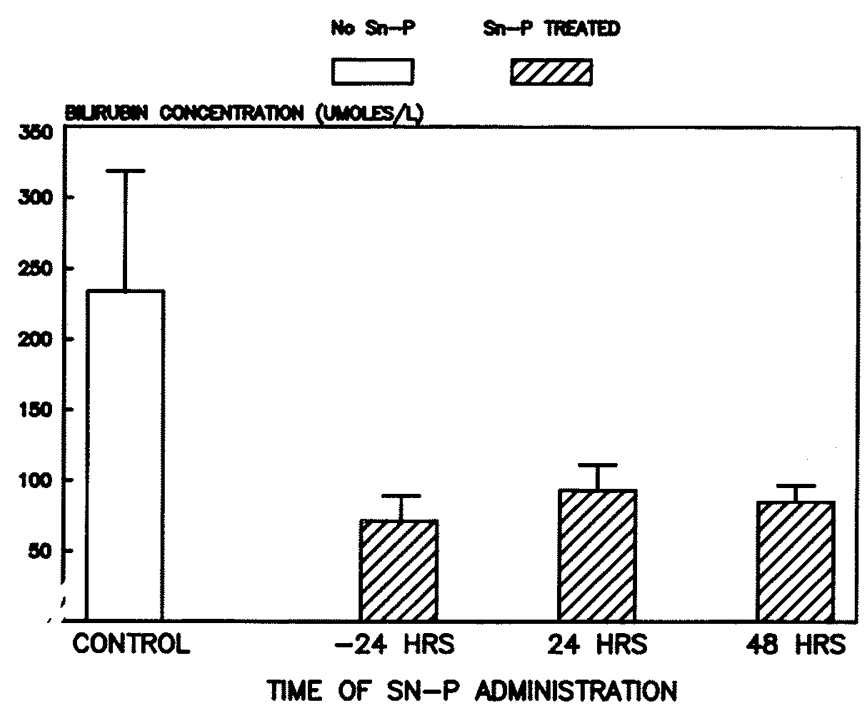

Fig. 1. Total serum bilirubin concentrations after $\mathrm{SnP}$ treatment. Values are mean $\pm \mathrm{SD}$.

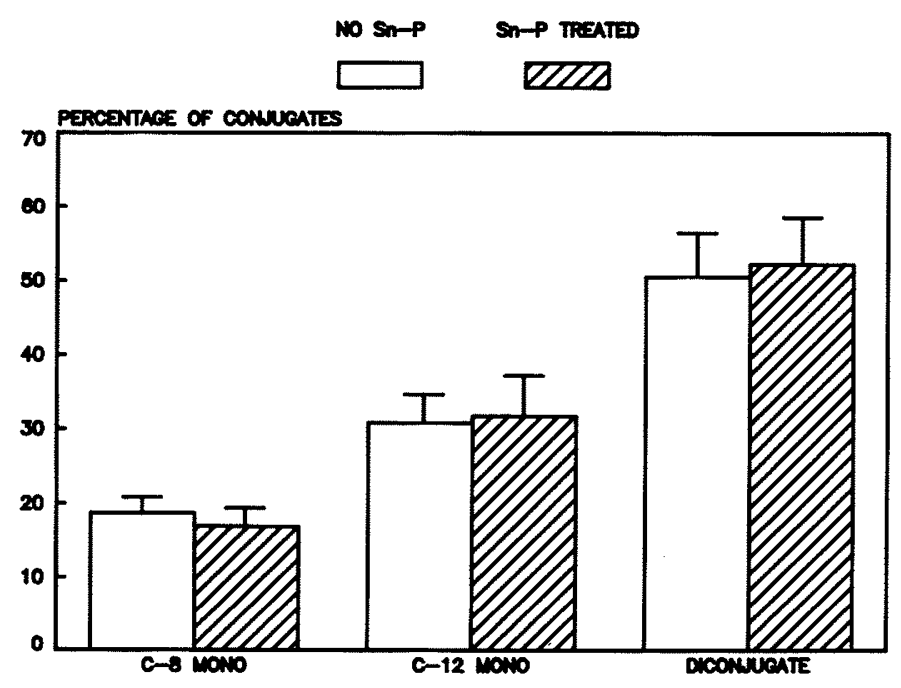

Fig. 2. Distribution of serum bilirubin monoconjugates (C-8 monoester and C-12 monoester) and diconjugates after SnP treatment and control ligated rats.

distribution of serum bilirubin monoconjugate and diconjugate fractions as compared to nontreated ligated control animals.

Figure 3 shows the distribution of bilirubin fractions in the urine samples of both control ligated and SnP-treated rats. Similar values were obtained for all animals tested.

Figure 4 illustrates the values for the serum bilirubin-protein conjugates in the four groups. The serum bilirubin-protein conjugate concentrations in the control cholestatic rats were significantly higher than the values in all SnP-treated animals $(p<$ $0.001)$. The lowest mean serum bilirubin-protein conjugate level was present in group II, the rats that received SnP $24 \mathrm{~h}$ prior to bile duct ligation. Although there appeared to be a trend that the longer the time the rats were exposed to $\mathrm{SnP}$ the lower the concentration of bilirubin-protein conjugates, the differences between the SnP-treated groups were not statistically different from one another.

\section{DISCUSSION}

Biliary excretion appears to be a major route of elimination of $\mathrm{SnP}$ in rats (10-12). Studies by Kappas et al. (17) revealed no adverse effect on the excretion of bilirubin conjugates in the bile of bile duct cannulated rats treated with heme and heme plus 

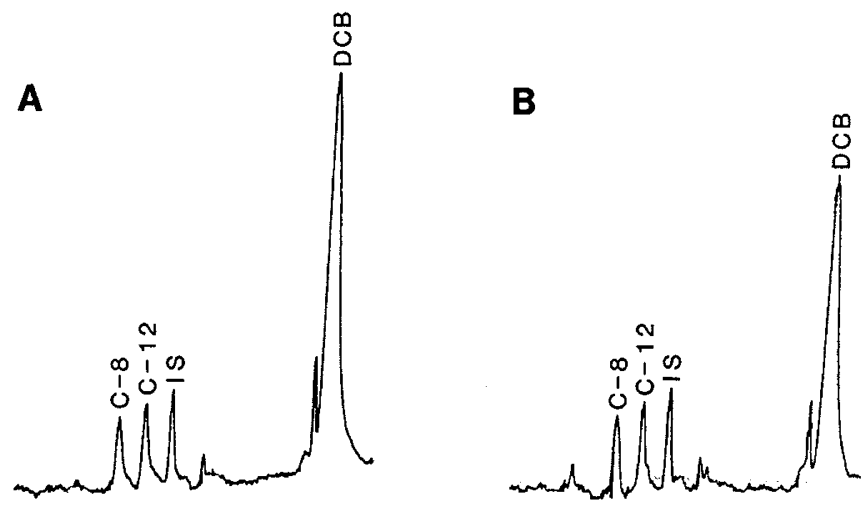

Fig. 3. $A$, chromatogram depicting the distribution of bilirubin conjugates in the urine of a SnP-treated rat. $B$, chromatogram depicting the distribution of bilirubin conjugates in the urine of a control ligated rat. The diester was the predominant conjugate in all instances. $C-8, \mathrm{C}-8$ monoester; $C$-12, C-12 monoester; $D C B$, diester; $I S$, internal standard.

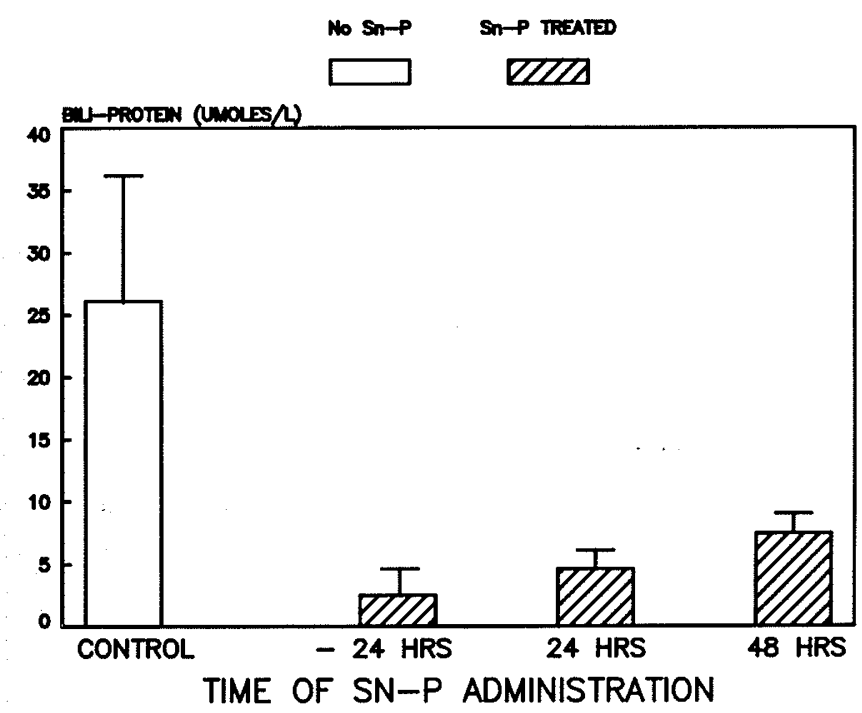

Fig. 4. Serum bilirubin-protein conjugate values in control ligated and $\mathrm{SnP}$ treated rats. Values are mean $\pm \mathrm{SD}$.

SnP. In situations in which biliary excretion may be impaired, i.e. neonatal physiologic cholestasis, the metabolism and effectiveness of SnP may be altered. Our results in adult cholestatic rats demonstrate the continued effectiveness of SnP in suppressing serum bilirubin concentrations in animals with bile duct ligation and hence absent biliary excretion of SnP. No adverse effects on bilirubin conjugation were observed. Both SnP-treated and control rats had similar percentages of bilirubin monoconjugates and diconjugates in serum and urine.

It is possible that dissociation of the central tin atom from $\mathrm{SnP}$ could occur. Whereas SnP is a potent inhibitor of heme oxygenase, inorganic tin stimulates heme oxygenase activity resulting in increased bilirubin production $(18,19)$. However, it is unlikely that there is release of inorganic tin by physiologic pathways inasmuch as $\mathrm{SnP}$ is not a substrate for heme oxygenase. If tin did dissociate from the SnP molecule, our findings suggest that the inhibitory effect of SnP far outweighed the stimulatory effect of elemental tin on heme oxygenase activity in vivo.

Cholestasis has also been associated with enhancement of heme oxygenase activity $(4,20-22)$. Regardless of the timing of administration of $\mathrm{SnP}$ around bile duct ligation, $\mathrm{SnP}$ significantly and effectively lowered serum bilirubin to comparable levels. The contribution of cholestasis to hyperbilirubinemia from increased red blood cell destruction and heme oxygenase activity was readily overcome by $\mathrm{SnP}$ treatment.
The formation of covalently linked bilirubin-protein conjugates in serum is thought to be a nonenzymatic interaction between bilirubin monoconjugates and diconjugates and serum proteins $(23,24)$. Our results demonstrate a direct correlation between the concentrations of bilirubin mono- and diconjugates and bilirubin-protein conjugate concentrations. All rats were cholestatic for an identical period of time $(72 \mathrm{~h})$, but animals exposed to SnP for the longest period of time (group II) had the lowest bilirubin-protein conjugate levels. It is unlikely that SnP directly bound to serum proteins making them unavailable for bilirubin-protein conjugate formation, because SnP has been shown to have weak binding to serum albumin and apomyoglobin (25). Rather, our results support a concentration dependence for bilirubin-protein conjugate formation.

In summary, $\mathrm{SnP}$ effectively lowered serum bilirubin levels in adult bile duct ligated rats. No adverse effect was observed on bilirubin conjugating mechanisms. Disruption of the normal biliary excretory pathway for SnP did not alter the drug's effectiveness or result in any observable toxicity. While our results are encouraging for the potential use of SnP in cholestatic conditions including neonatal physiologic jaundice and its associated physiologic cholestasis, further carefully controlled studies are warranted in both animal and human newborns before widespread use of this drug can be recommended.

\section{REFERENCES}

1. Drummond GS, Kappas A 1981 Prevention of neonatal hyperbilirubinemia by tin protoporphyrin IX, a potent competitive inhibitor. Proc Natl Acad Sci USA 78:6466-6470

2. Yoshinaga T, Sassa S, Kappas A 1982 Purification and properties of bovine spleen heme oxygenase. J Biol Chem 257:7778-7785

3. Tenhunen R, Marver HS, Schmid R 1969 Microsomal heme oxygenase Characterization of the enzyme. J Biol Chem 244:6388-6394

4. McMillan JJ, Vreman HJ, Stevenson DK 1987 Tin-protoporphyrin decreases bilirubin production and hyperbilirubinemia in obstructive jaundice. Pediatr Research 21:273A(abstr)

5. Anderson KE, Simionatto CS, Drummond GS, Kappas A 1986 Disposition of tin-protoporphyrin and suppression of hyperbilirubinemia in humans. Clin Pharmacol Ther 39:510-520

6. Cornelius CE, Rodgers PA 1984 Prevention of neonatal hyperbilirubinemia in rhesus monkeys by tin-protoporphyrin. Pediatr Res 18:728-730

7. Milleville GS, Levitt MD, Engel RR 1985 Tin protoporphyrin inhibits carbon monoxide production in adult mice. Pediatr Res 19:94-96

8. Sassa S, Drummond GS, Bernstein SE, Kappas A 1983 Tin-protoporphyrin suppression of hyperbilirubinemia in mutant mice with severe hemolytic anemia. Blood 61:1011-1013

9. McDonagh AF, Palma LA 1985 Tin-protoporphyrin: a potent photosensitizer of bilirubin destruction. Photo Chem Photobiol 42:261-264

10. Whitington PF, Moscioni AD, Gartner LM 1987 The effect of tin (IV)protoporphyrin-IX on bilirubin production and excretion in the rat. Pediatr Res 25:487-491

11. Anderson KE, Simionatto CS, Drummond GS, Kappas A 1984 Tissue distribution and disposition of tin-protoporphyrin, a potent competitive inhibitor of heme oxygenase. J Pharm Exp Ther 228:327-333

12. Simionatto CS, Anderson KE, Drummond GS, Kappas A 1985 Studies on the mechanism of Sn-protoporphyrin suppression of hyperbilirubinemia. Inhibition of heme oxidation and bilirubin production. J Clin Invest 75:513521

13. Balistreri WF, Heubi JE, Suchy FJ 1983 Immaturity of the enterohepatic circulation in early life: Factors predisposing to "physiologic" maldigestion and cholestasis. J Pediatr Gastroenterol Nutr 2:346-354

14. Suchy FJ, Balistreri WF, Heubi JE, Searcy JE, Levin RS 1981 Physiologic cholestasis: Elevation of the primary serum bile acid concentrations in normal infants. Gastroenterology 80:1037-1041

15. Rosenthal P, Blanckaert N, Kabra P, Thaler MM 1981 Liquid chromatographic determination of bilirubin and its conjugates in rat serum and human amniotic fluid. Clin Chem 27:1704-1707

16. Blanckaert N, Servaes R, Leroy P 1986 Measurement of bilirubin-protein conjugates in serum and application to human and rat sera. $\mathrm{J}$ Lab Clin Med 108:77-87

17. Kappas A, Simionatto CS, Drummond GS, Sassa S, Anderson KE 1985 The liver excretes large amounts of heme into bile when heme oxygenase is inhibited competitively by Sn-protoporphyrin. Proc Natl Acad Sci USA 82:896-900

18. Drummond GS, Kappas A 1980 Metal ion interactions in the control of haem oxygenase induction in liver and kidney. Biochem J 192:637-648

19. Kappas A, Maines MD 1976 Tin: a potent inducer of heme oxygenase in kidney. Science 192:60-62

20. Stevenson DK, Salomon WL, Moore LY, Trudgen JK, Cowan BC, Vreman HJ, Kwong LK 1984 Pulmonary excretion rate of carbon monoxide as an index of total bilirubin production in adult male Wistar rats with common 
bile duct ligation. J Pediatr Gastroenterol Nutr 3:790-794

21. Salomon WL, Vreman HJ, Kwong LK, Stevenson DK 1986 Red cell destruction and bilirubin production in adult rats with short-term biliary obstruction. J Pediatr Gastroenterol Nutr 5:806-810

22. Schacter BA, Joseph E, Firneisz G 1983 Effect of cholestasis produced by bile duct ligation on hepatic heme and hemoprotein metabolism in rats. Gastroenterology 84:227-235

23. Weiss JS, Gautam A, Lauff JJ, Sundberg MW, Jatlow P, Boyer JL, Seligson D
1983 The clinical importance of a protein-bound fraction of serum bilirubin in patients with hyperbilirubinemia. N Engl J Med 309:147-150

24. Lauff JJ, Kasper ME, Wu TW, Ambrose RT 1982 Isolation and preliminary characterization of a fraction of bilirubin in serum that is firmly bound to protein. Clin Chem 28:629-637

25. Breslow E, Chandra R, Kappas A 1986 Biochemical properties of the heme oxygenase inhibitor, Sn-protoporphyrin. Interactions with apomyoglobin and human serum albumin. J Biol Chem 261:3135-3137

\section{Announcement \\ International Symposium on Growth Abnormalities}

An International Symposium on growth abnormalities will be held in Bologna, Italy, June 22-24, 1988 . Main topics: physiology of growth and growth disturbances (growth hormone deficiencies, genetic, adrenogenital, and Turner's syndromes, celiac, and onco-hematologic diseases) GH; GRF, and alternative treatments for growth failure.

The symposium falls within the celebration of the 9th Centenary of the University of Bologna and it will include lectures by invited speakers and selected oral and poster presentations.

Scientific committee: E. Cacciari (I), J. R. Bierich (FRG), S. Raiti (USA).

The deadline for submission of abstracts is March 15, 1988.

For further informations please contact: Scientific Secretariat, International Symposium on Growth Abnormalities, Clinica Pediatrica II dell'Università, Via Massarenti, 11, 40138 Bologna, Italy. 